\title{
The fight against doping from the perspective of Swiss athletes and coaches
}

\section{ANTIDOPING / COACHING / ELITE SPORTS}

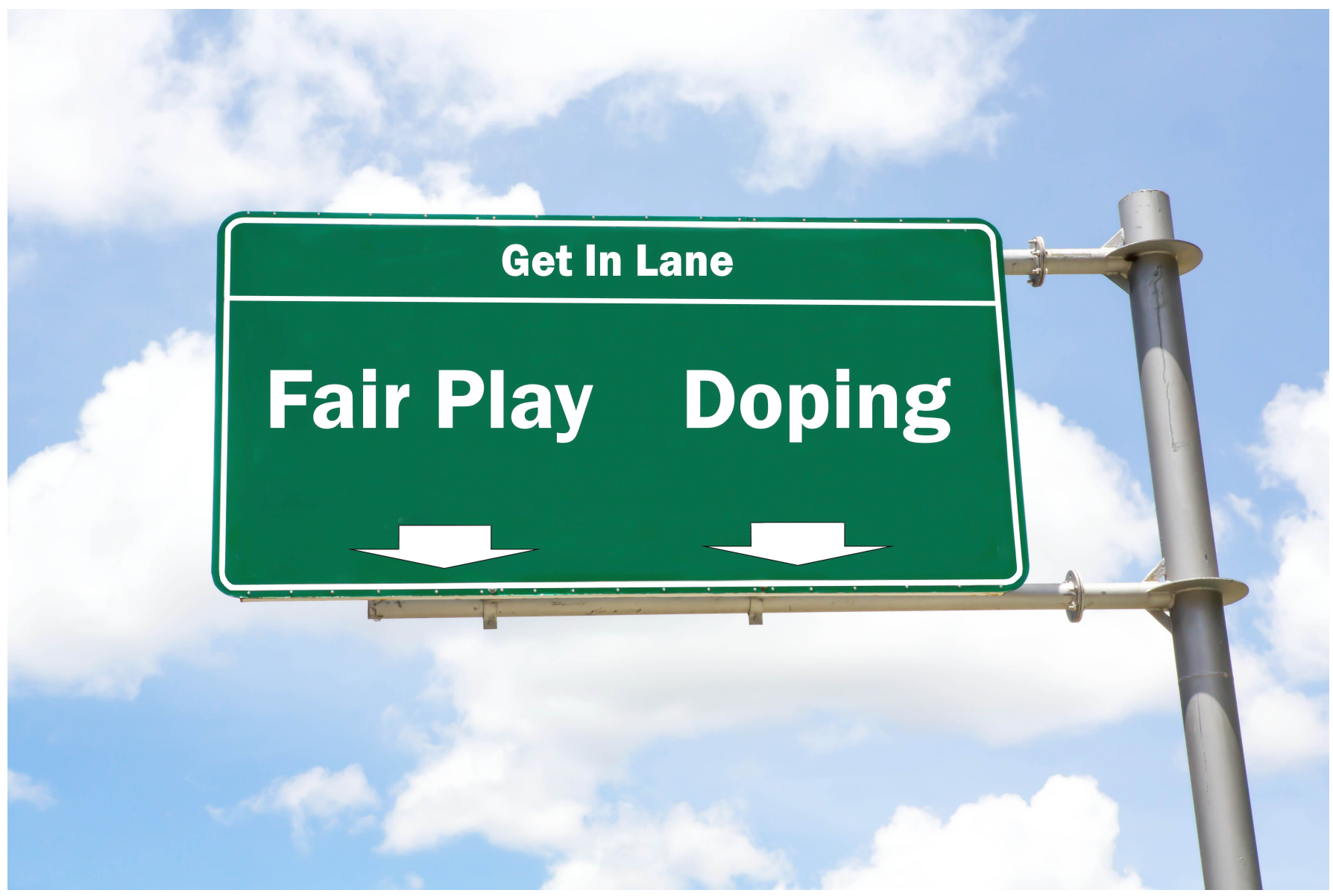

\section{Gebert $A^{1}$, Stamm $H^{1}$, Kamber $M^{2}$, Lamprecht $M^{1}$}

${ }^{1}$ Lamprecht und Stamm Sozialforschung und Beratung, Zurich, Switzerland

${ }^{2}$ Antidoping Switzerland Foundation, Bern, Switzerland

\section{Abstract}

The fight against doping is not primarily a fight against fallible athletes and coaches but rather a fight for clean athletes and coaches. Therefore, the present study aimed to investigate how Swiss athletes and coaches perceive the doping problem and the current anti-doping policy. Two online surveys of 1040 Swiss squad coaches and 588 Swiss athletes of various sports were conducted in 2016 and 2017. 41.5\% of athletes 
and $31.5 \%$ of coaches identified a serious doping problem in their sport. This perception varied significantly by sport $(\mathrm{p} \leq 0.001) .94 .2 \%$ of athletes and $91.7 \%$ of coaches argued in support of a strict prohibition of doping. The risk of getting caught when using banned substances and methods in Switzerland was perceived as high by $83.9 \%$ of athletes and $88.2 \%$ of coaches. A vast majority of athletes (92.5\%) and of coaches (92.0\%) thought that the state of the fight against doping differs greatly throughout the world. Greater international cooperation was seen as the most important measure in the future fight against doping. In conclusion, athletes and coaches consider doping to be a serious problem and strongly support a strict anti-doping policy all over the world.

\section{Zusammenfassung}

Der Kampf gegen Doping ist nicht in erster Linie ein Kampf gegen fehlbare Athleten und Trainer, sondern ein Kampf für saubere Athleten und Trainer. Deshalb bestand das Ziel der vorliegenden Studie darin, zu untersuchen, wie Schweizer Sportler und Trainer das Dopingproblem und die aktuelle Anti-Doping-Politik wahrnehmen. In den Jahren 2016 und 2017 wurden zwei Onlinebefragungen mit 1040 Schweizer Kadertrainern und mit 588 Schweizer Athleten aus verschiedenen Sportarten durchgeführt. 41,5\% der Athleten und 31,5\% der Trainer erkannten ein ernsthaftes Dopingproblem in ihrer Sportart. Diese Wahrnehmung variierte erheblich zwischen verschiedenen Sportarten ( $\mathrm{p} \leq 0,001) .94,2 \%$ der Athleten und 91,7\% der Trainer sprachen sich für ein strenges Dopingverbot aus. Das Risiko, in der Schweiz bei der Anwendung verbotener Substanzen und Methoden erwischt zu werden, wurde von 83,9\% der Athleten und 88,2\% der Trainer als hoch eingeschätzt. Zudem war eine überwiegende Mehrheit der Athleten (92,5\%) und Trainer (92,0\%) der Meinung, dass sich der Stand der Dopingbekämpfung international auf sehr unterschiedlichem Niveau befindet. Entspreched wurde eine verstärkte internationale Zusammenarbeit als wichtigste Massnahme im zukünftigen Kampf gegen Doping genannt. Es gilt festzuhalten, dass sowohl Athleten als auch Trainer Doping als ernsthaftes Problem wahrnehmen und sie daher eine strenge Anti-Doping-Politik auf der ganzen Welt mit Nachdruck unterstützen.

\section{Introduction}

Swiss athletes have a strict attitude against the use of doping [1,2]. In 2010, a survey showed that the statements "doping creates bad role models", “doping damages the image of sport”, and "doping contradicts the ideal of fair play” were supported by $93 \%$ to $97 \%$ of all interviewed Swiss athletes [1]. Not only Swiss athletes consider doping to be unethical and unfair, this view is shared by athletes worldwide [3-5].

Since the consumption of performance enhancing substances not only destroys equal opportunities in sport but can also cause serious health consequences for athletes [6,7], a ban on performance enhancing substances or methods and a well-organised fight against doping is justified [8]. Between 2004 and 2017 the number of samples analysed per year by the World Anti-Doping Agency (WADA) increased by around $100 \%$ from 169,187 to 322,050 [9,10]. Although, the number of banned substances and methods also increased, the percentage of adverse and atypical findings remained stable at nearly $2 \%$. In Switzerland, the responsible authority Antidoping Switzerland carried out 2456 doping tests in 2017 with a total of 3416 doping samples (2016: 2465 controls with 3269 samples) [11]. Of these samples, 2443 were urine samples of which 1469 were collected out of competition and further 973 samples were blood samples of which 925 
were collected out of competition. In only twelve cases a report regarding a possible anti-doping rule violation was filed with the Swiss Olympic Disciplinary Chamber for Doping Cases. Accordingly, the fight against doping requires large personal and financial resources [11-13].

A clear majority of athletes considers testing for banned substances to be an effective measure to prevent the use of doping [14-16]. However, various studies also show that a remarkable proportion of athletes is of the opinion that the chance of being tested is small or that the doping test programmes are insufficient [15-18]. Accordingly, in addition to regular doping tests, further measures such as prevention and information are necessary [19,20], because the knowledge about doping is insufficient in different groups of athletes $[4,18,20,21]$. Studies repeatedly reported that for athletes the coach is an important source of information regarding nutritional supplements and doping [20,22-24]. According to a survey of French coaches $98 \%$ considered that they play a role in doping prevention but $80 \%$ thought that they were badly trained for this task [25].

Moston et al. [17] concluded that further measures to prevent doping should focus on possibilities to increase the perceived certainty of being caught by drug testing authorities in both athletes and coaches. Against this background, it seems important to know and monitor the athletes' and coaches' attitudes towards doping and doping prevention. Therefore, the aim of the present study was to show how Swiss athletes and coaches do perceive the doping problem and the fight against doping. More specifically, the following research questions will be addressed:

1. How do athletes and coaches perceive the problem of doping on national and international level? Are there differences according to sports?

2. How do athletes and coaches appraise the fight against doping in Switzerland?

3. How do athletes and coaches want to regulate doping in the future?

\section{Methods}

\section{Procedure}

The data used in this article originate from two online surveys aimed at Swiss athletes and at Swiss coaches. All potential respondents were informed in advance about the purpose of the study and the participation in all surveys was voluntary and anonymous. According to Art. 2 HRA (Human Research Act) and to Art. 25 HRO (Human Research Ordinance) an ethical committee's approval is not required for anonymised surveys in Switzerland.

\section{Population}

In May 2017, 2044 athletes were invited to an online survey on their perception of the fight against doping and of Antidoping Switzerland. These were exclusively persons who had been tested by Antidoping Switzerland during the previous 36 months. A total of 588 athletes completed the questionnaire, which corresponds to a participation rate of $28.8 \%$. The interviewed athletes came from different sports such as track and field (8.3\%), ice hockey (6.1\%), cycling (road/track) (5.7\%), mountainbike (5.3\%), Nordic skiing (5.1\%), swimming (4.7\%), and triathlon/duathlon (4.7\%). From other sports, fewer than 20 athletes each participated in the survey. Already in the years 2005 and 2010 such athlete surveys were carried out with a somewhat different sample of athletes [1].

For the survey of sports coaches, the e-mail addresses of all Swiss squad coaches were provided by the 
educational organisation "youth+sports" and an invitation mail for the online survey was sent to 3862 coaches in October 2016. Of these, 1040 coaches completed the questionnaire (participation rate: 26.9\%). The background of coaches differed substantially. 53.0\% of coaches worked with elite athletes which performed at the international or the national level or with youth athletes which were classified as national talents and the remaining coaches worked with elite athletes and talents at the regional and local levels. The interviewed coaches came from different sports such as soccer (16.4\%), alpine skiing (8.3\%), ice hockey (6.6\%), handball (6.6\%), track and field (6.5\%), orienteering (5.2\%), gymnastics (4.7\%), volleyball (4.2\%), tennis (3.8\%), triathlon/duathlon (3.6\%), Nordic skiing (3.5\%), swimming (2.7\%), floorball (2.4\%), sport climbing (2.2\%). From other sports, fewer than 20 coaches each participated in the survey.

\section{Questionnaire}

The seriousness of the doping problem in sport was recorded for international top-level, national top-level, and national mass participation sport and the question wording was: "How big a problem is doping in your sport?”. Response options included a 4-point scale ("very serious problem”, "serious problem”, "small problem", "no problem at all") and the possibility to abstain from an answer ("don’t know").

Athletes and coaches were asked to rate six statements (I1 to I6, see Table 2) relating to the fight against doping. Response options included a 4-point scale (“completely agree”, “agree”, “don’t really agree”, “don’t agree at all”) and the possibility to abstain from an answer (“don’t know”). I5 and I6 were adapted from Moston et al. [17].

With respect to the test frequency in competition and out of competition the athletes and coaches were asked separately: "Are you / your athletes tested frequently enough? Do you think the number of controls is “too high”, "just right”, “too low”, “don’t know”?”. Further questions were: “Are you able to get enough information about doping?” (“yes"/“no”) and: "When you were trained to be a coach, was there enough focus on the issue of doping?" ("yes”/“no", coaches only). Additionally, the athletes were asked who informed them about doping and they could choose multiple sources of information, namely "coach", "physician”, "other athletes", "sport association and club”, “Antidoping Switzerland”, "Swiss Olympic", "BASPO (Federal Office for Sport) ”, "international sport association”, "media (newspapers, magazines)”, "parents", "other sources of information", "was not informed at all”).

Athletes and coaches were finally asked about their attitude towards the future regulation of doping. The question wording of the first question was: "How should doping be regulated in the future?". Three answers were possible, namely: "Doping should be strictly prohibited", "Doping should be permitted under medical supervision”, and: "Doping should be permitted without constraints". Furthermore, the importance of various measures for the future regulation of doping (see Table 3) was recorded.

\section{Statistical analysis}

Statistical analyses were performed with SPSS software (version 24.0). Descriptive statistics were calculated to describe the athletes' and coaches' perceptions and assessments. To examine significant differences between team sport and individual sport athletes or coaches $\mathrm{x} 2$ statistics for nominal variables and Mann-Whitney U tests for categorical variables were applied [26]. The Kruskal-Wallis test was used to determine significant differences in the perception of the doping problem across all sports [26]. P-values lower than 0.05 were considered significant. 


\section{Results}

\section{Perception of the doping problem}

$41.5 \%$ of the interviewed athletes and $31.5 \%$ of the interviewed coaches identified a serious doping problem at the international top-level of their sport (Figure 1). With regard to the national top-level and the national mass participation sport, they were less critical.

Both athletes $(p \leq 0.001)$ and coaches $(p \leq 0.001)$ from individual sports considered their sport more vulnerable to doping than respondents from team sports. Moreover, the perception of the interviewed athletes and coaches varied significantly by their sport ( $\mathrm{p} \leq 0.001)$. In which sports a high proportion of athletes and coaches thought that doping was a serious or very serious problem at the international toplevel of their sport is shown in Table 1.

\section{Assessment of the fight against doping}

An overwhelming majority of athletes and coaches thought that doping contradicts the principle of fair play and that the fight against doping in Switzerland is exemplary (Table 2). It is notable that a clear majority of athletes and coaches believed that the fight against doping is at very different levels of quality throughout the world, that doping controls are more strict in Switzerland than in other countries and that people who use doping in Switzerland have a high risk of being caught. At the same time, less than one third of athletes and coaches assessed the risk of being caught in other countries as high.

Nevertheless, only an exceedingly small percentage of Swiss athletes and coaches appraised the frequency of doping controls in and out of competition as too high (Figure 2). Every fourth athlete or coach considered the control frequency even as too low.

\begin{tabular}{|l|l|l|}
\hline Athletes & total number & $\%$ \\
\hline swimming & 22 & 95 \\
\hline track and field & 42 & 88 \\
\hline cycling (road/track) & 27 & 63 \\
\hline Nordic skiing & 24 & 58 \\
\hline triathlon/duathlon & 21 & 48 \\
\hline mountainbike & 24 & 38 \\
\hline ice hockey & 26 & 15 \\
\hline & & \\
\hline & & \\
\hline & & \\
\hline & & \\
\hline
\end{tabular}

\begin{tabular}{|l|l|l|}
\hline Coaches & total number & $\%$ \\
\hline track and field & 64 & 94 \\
\hline swimming & 24 & 79 \\
\hline Nordic skiing & 34 & 74 \\
\hline triathlon/duathlon & 32 & 63 \\
\hline tennis & 34 & 41 \\
\hline soccer & 127 & 33 \\
\hline ice hockey & 56 & 27 \\
\hline volleyball & 31 & 23 \\
\hline gymnastics & 37 & 22 \\
\hline alpine skiing & 70 & 19 \\
\hline handball & 51 & 6 \\
\hline floorball & 21 & 5 \\
\hline orienteering & 46 & 0 \\
\hline
\end{tabular}




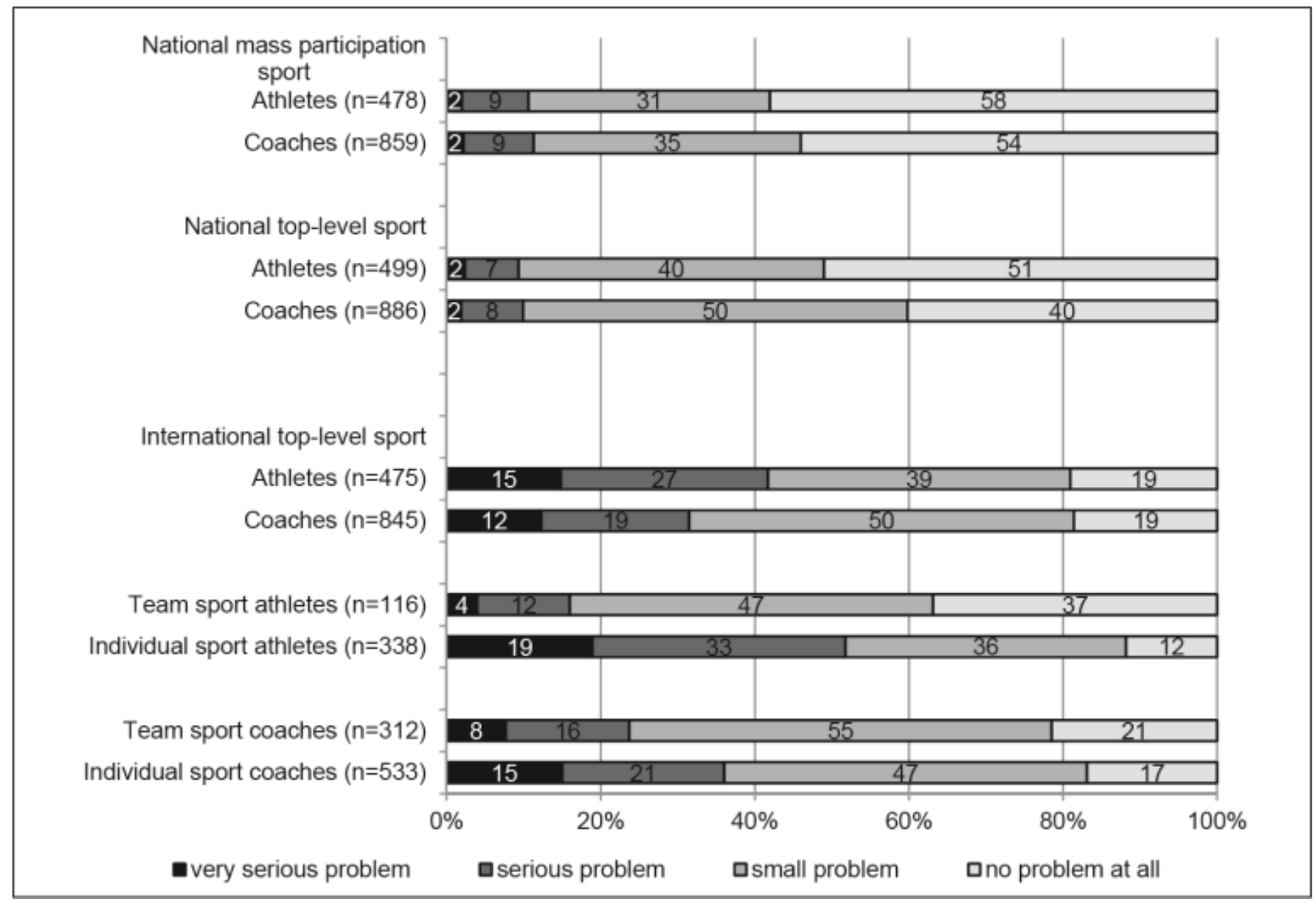

Figure 1

$96.5 \%$ of athletes were able to get enough information about doping. Antidoping Switzerland (64.3\%), coaches and coaching staff (55.5\%), federation and club (52.5\%), and the physician (48.2\%) were the most common sources of information for athletes. With 81.7\%, the proportion of coaches who are able to get enough information about doping was lower and differed slightly between coaches of national and international elite athletes (84.0\%) and coaches of regional squads ( $79.1 \%, \mathrm{p}=0.042$ ). Additionally, $57.1 \%$ of coaches considered that the issue of doping was sufficiently addressed during their coach education. In this respect, there was also a difference between coaches of national and international elite athletes $(62.8 \%)$ and coaches of regional squads $(50.6 \%, \mathrm{p} \leq 0.001)$.

\section{Future regulation of doping}

$94.2 \%$ of athletes and $91.7 \%$ of coaches advocate a strict prohibition of doping. As Table 3 shows, a greater international cooperation was considered as the most effective measure in the future fight against doping. Additionally, various other measures were considered as important by a majority of athletes and coaches. In particular, the coaches saw stricter penalties for the entourage (physicians, coaches, masseurs, support team etc.) as an important measure in the fight against doping. 


\section{Discussion}

Doping is often perceived as a problem of athletes and their coaches who want to increase performance by using banned substances and means. Accordingly, the fight against doping seems to be primarily a fight against fallible athletes and coaches. Thereby, it is often forgotten that the fight against doping is above all a fight for clean athletes and coaches. The present study shows, in line with international research, that an overwhelming majority of athletes and coaches strongly oppose doping and clearly support strict doping controls [3-5] since the consumption of banned substances destroys equal opportunities in sport. $32 \%$ of athletes and $42 \%$ of coaches believe that there is a serious doping problem in their sport. This finding is not in line with a survey of Australian athletes and coaches, in which $77 \%$ of athletes and $74 \%$ of coaches agreed to the statement that the problem of performance-enhancing drug use in sport (in general) is serious [17]. However, in the present study respondents were not asked for an assessment of sport in general but for an assessment of their own sport. Their perception differed significantly according to level and sport. In sports such as swimming, track and field, cycling, and Nordic skiing a majority of athletes and coaches identified a doping problem.

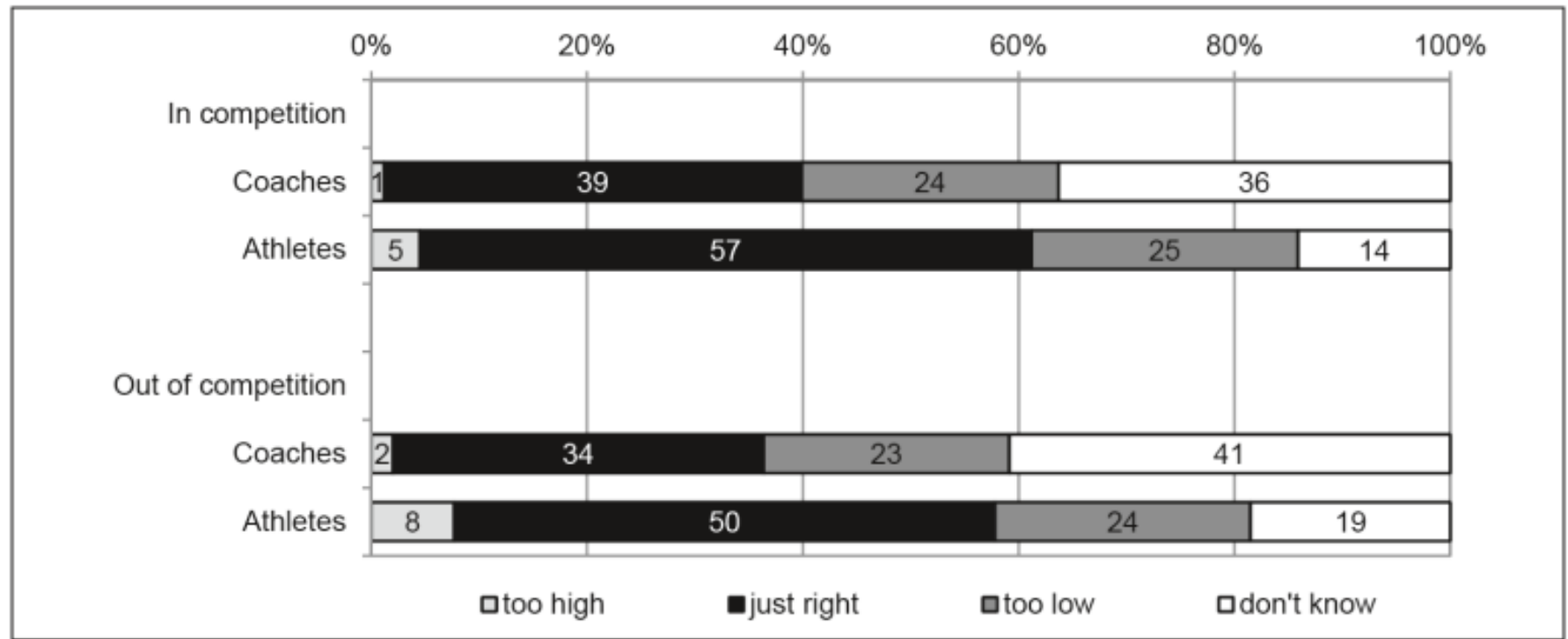




\begin{tabular}{|l|l|l|l|}
\hline \multicolumn{1}{|l|}{} & & Athletes & Coaches \\
\hline I1 & Doping contradicts the principle of fair play. & 94.8 & [not asked] \\
\hline 13 & $\begin{array}{l}\text { The fight against doping in Switzerland is exemplary. } \\
\text { The fight against doping is at very different levels } \\
\text { throughout the world. }\end{array}$ & 91.6 & 92.0 \\
\hline 14 & $\begin{array}{l}\text { Doping controls in many other countries are less } \\
\text { strict than in Switzerland. }\end{array}$ & 96.8 \\
\hline 15 & $\begin{array}{l}\text { People who use doping in Switzerland have a high } \\
\text { risk of being caught. }\end{array}$ & 83.9 & 85.9 \\
\hline 16 & $\begin{array}{l}\text { People who use doping in other countries have a high } \\
\text { risk of being caught. }\end{array}$ & 31.0 & 88.2 \\
\hline
\end{tabular}

With regard to the fight against doping, differences were seen less between various sports but more between different countries. From the athletes' and coaches' point of view, doping is not consistently fought in various countries. According to their perception, the risk of getting caught by using banned substances and means differs substantially between countries and is perceived as high in Switzerland by a majority of athletes (84\%) and coaches (88\%). This is an important condition for successful doping prevention [17]. In comparison, $63 \%$ of athletes and $48 \%$ of coaches thought that Australia's anti-doping regime is effective in deterring athletes from taking performance-enhancing drugs [17].

The results of the present study suggest that athletes and coaches considered doping controls as an effective measure against doping [14-16]. Only very few respondents appraised the frequency of doping controls in and out of competition as too high in Switzerland. In addition to a high frequency of tests, stricter penalties are particularly desired for convicted athletes and also for their entourage and coaches. The findings of the present study also indicate that additional weight should be placed on information and prevention in the future fight against doping. While only $4 \%$ of athletes felt insufficiently informed about doping, this proportion was $18 \%$ among coaches. Furthermore, $43 \%$ of coaches considered that the issue of doping was insufficiently addressed during their coaches' education. Since the coach was mentioned as a source of information by $56 \%$ of athletes and previous research also confirmed coaches as important source of information with respect to doping and nutritional supplements [20,22-24], a "train the trainer" approach could be promising. A survey of German coaches of different performance levels also showed deficits regarding doping-specific knowledge [20]. Only 55\% had doping treated as an issue during the coaches' education, $66 \%$ wanted more information, and between $13 \%$ and $49 \%$ felt insufficiently informed. As the most important measure in the future fight against doping, both athletes and coaches were calling for a greater international cooperation. How international harmonization of anti-doping policy could work is shown in several studies [27-29].

With a large number of athletes and coaches the data basis of the present study is excellent. However, one limitation of these surveys is that the samples could not be determined in an absolutely identical way. Different sources had to be used to contact athletes and coaches. In addition, the interviewed athletes were exclusively persons who had been tested by Antidoping Switzerland during the previous 36 months which 
could be a relevant selection bias, because perception of anti-doping efforts might change in athletes who recently have been tested.

Social desirability bias is another possible limitation of this kind of research. Since the present study is based on the assessments of athletes and coaches and not on personal information about the use of banned substances and means, the effect of social desirability should be limited. However, no statement can be made as to how widespread doping is in Swiss high-level sports.

\begin{tabular}{|c|c|c|c|c|}
\hline & very important & fairly important & not very important & totally unimportant \\
\hline \multicolumn{5}{|c|}{ Greater international cooperation } \\
\hline Athletes & 70.0 & 25.1 & 3.3 & 1.6 \\
\hline Coaches & 76.6 & 19.7 & 2.7 & 0.9 \\
\hline \multicolumn{5}{|c|}{ Stricter penalties for athletes who dope } \\
\hline Athletes & 59.6 & 29.9 & 9.5 & 1.0 \\
\hline Coaches & 62.3 & 30.9 & 5.8 & 0.9 \\
\hline
\end{tabular}

Penalties for entourage [physicians, coaches, masseurs, support team etc.]

\begin{tabular}{l|l|l|l|l|}
\hline Athletes & 52.2 & 34.8 & 11.1 & 1.9 \\
\hline Coaches & 67.5 & 26.7 & 4.6 & 1.2
\end{tabular}

More doping controls

\begin{tabular}{|l|l|l|l|l|}
\hline Athletes & 38.4 & 48.7 & 10.7 & 2.1 \\
\hline Coaches & 39.0 & 49.3 & 10.1 & 1.6
\end{tabular}

More money available for fight against doping

\begin{tabular}{|l|l|l|l|l|}
\hline Athletes & 41.1 & 41.8 & 14.2 & 2.9 \\
\hline Coaches & 45.3 & 42.6 & 10.2 & 1.9 \\
\hline
\end{tabular}

More information and prevention

\begin{tabular}{|c|c|c|c|c|}
\hline Athletes & 37.7 & 44.3 & 16.4 & 1.6 \\
\hline Coaches & 47.4 & 41.2 & 10.6 & \\
\hline
\end{tabular}

Doping samples retained for a long time and penalties imposed subsequently

\begin{tabular}{|l|l|l|l|l|}
\hline Athletes & 41.2 & 31.3 & 20.4 & 7.0 \\
\hline Coaches & 53.2 & 31.9 & 11.4 & 3.5
\end{tabular}

Doping should be prohibited by law

\begin{tabular}{|l|l|l|l|l|}
\hline Athletes & 34.3 & 36.5 & 23.2 & 6.0 \\
\hline Coaches & 38.3 & 35.4 & 19.9 & 6.4 \\
\hline
\end{tabular}

Table 3

\section{Conclusions}

Athletes and coaches consider doping to be a serious problem in international top-level sport especially in sports such as swimming, track and field, cycling, and Nordic skiing. They strongly support a strict antidoping policy all over the world, which also includes a high control frequency and strict penalties. More international cooperation is seen as the most important measure in the future fight against doping. 


\section{Conflict of Interest}

The authors declare no conflicts of interest. $\square$

\section{Corresponding author $\square$}

Angela Gebert

Lamprecht und Stamm

Sozialforschung und Beratung

Forchstrasse 212

CH-8032 Zurich, Switzerland

Tel. +41442606760

E-Mail: angela.gebert@lssfb.ch $\square$

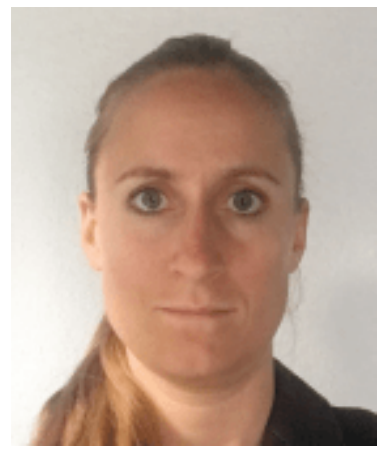

\section{References}

1. Stamm H, Lamprecht M, Kamber M. Attitudes towards doping - A comparison of elite athletes, performance oriented leisure athletes and the general population. ejss. 2014;11(2):171-89.

2. Stamm H, Lamprecht M, Kamber M, Marti B, Mahler N. The public perception of doping in sport in Switzerland, 1995-2004. J Sports Sci. 2008;26(3):235-42.

3. Laure P, Lecerf T, Friser A, Binsinger C. Drugs, recreational drug use and attitudes towards doping of high school athletes. Int J Sports Med. 2004;25(2):133-8.

4. Mottram D, Chester N, Atkinson G, Goode D. Athletes' knowledge and views on OTC medication. Int J Sports Med. 2008;29(10):851-5.

5. Bloodworth AJ, Petroczi A, Bailey R, Pearce G, McNamee MJ. Doping and supplementation: the attitudes of talented young athletes. Scand J Med Sci Sports. 2012;22(2):293-301.

6. Pope HG, Jr., Wood RI, Rogol A, Nyberg F, Bowers L, Bhasin S. Adverse health consequences of performance-enhancing drugs: an Endocrine Society scientific statement. Endocr Rev. 2014;35(3):341-75.

7. van Amsterdam J, Opperhuizen A, Hartgens F. Adverse health effects of anabolic-androgenic steroids. Regul Toxicol Pharmacol. 2010; 57(1):117-23.

8. Breitsameter C. How to justify a ban on doping? J Med Ethics. 2017;43(5):287-92.

9. WADA. 2004 Adverse Analytical Findings Reported by Accredited Laboratories [Internet]. 2004 [cited August 15, 2018]. Available from: https://www.wada-ama.org/sites/default/files/resources/files/WADA_LaboStatistics_2004.pdf.

10. WADA. 2007 Anti-Doping Testing Figures. Executive Summary. [Internet]. 2017 [cited August 15, 2018]. Available from: https://www.wada-ama.org/sites/default/files/resources/ files/2017_antidoping_testing_figures_en_0.pdf.

11. Annual Report 2017 [Internet]. Antidoping Switzerland. 2017 [cited July 17, 2018]. Available from: https://www.antidoping.ch/de/allgemein/stiftung-antidoping-schweiz/jahresberichte.

12. Mountjoy M, Miller S, Vallini M, Foster J, Carr J. International Sports Federation's fight to protect the clean athlete: are we doing enough in the fight against doping? Br J Sports Med. 2017;51(17):1241-2.

13. Dvorak J, Saugy M, Pitsiladis YP. Challenges and threats to implementing the fight against doping in sport. Br J Sports Med. 2014; 48(10):807-9.

14. Dunn M, Thomas JO, Swift W, Burns L, Mattick RP. Drug testing in sport: the attitudes and 
experiences of elite athletes. Int J Drug Policy. 2010;21(4):330-2.

15. Overbye M, Knudsen ML, Pfister G. To dope or not to dope: Elite athletes' perceptions of doping deterrents and incentives. Performance Enhancement \& Health. 2013;2:119-34.

16. Waddington I, Malcolm D, Roderick M, Naik R. Drug use in English professional football. Br J Sports Med. 2005;39(4):1-5.

17. Moston S, Engelberg T, Skinner J. Athletes' and coaches' perceptions of deterrents to performanceenhancing drug use. Int J Sport Policy. 2015;7(4):623-63.

18. International Literature Review: Attitudes, behaviours, knowledge and education - drugs in sport: Past, present and future [Internet]. World Anti-Doping Agency. 2006 [cited June 26, 2018]. Available from: https://www.wada-ama.org/sites/default/files/resources/files/backhouse_et_al_full_report.pdf.

19. Alaranta A, Alaranta H, Holmila J, Palmu P, Pietila K, Helenius I. Self-reported attitudes of elite athletes towards doping: differences between type of sport. Int J Sports Med. 2006;27(10):842-6.

20. Peters C, Schulz T, Oberhoffer R, Michna H. Doping and Doping Prevention: Knowledge, Attitudes and Expectations of Athletes and Coaches. DEUTSCHE ZEITSCHRIFT FÜR SPORTMEDIZIN. 2009;60(3):73-8.

21. Sekulic D, Tahiraj E, Zvan M, Zenic N, Uljevic O, Lesnik B. Doping Attitudes and Covariates of Potential Doping Behaviour in HighLevel Team-Sport Athletes; Gender Specific Analysis. J Sports Sci Med. 2016;15(4):606-15.

22. Morente-Sanchez J, Zabala M. Doping in sport: a review of elite athletes' attitudes, beliefs, and knowledge. Sports Med. 2013;43(6): 395-411.

23. Sundgot-Borgen J, Berglund B, Torstveit MK. Nutritional supplements in Norwegian elite athletesimpact of international ranking and advisors. Scand J Med Sci Sports. 2003;13(2):138-44.

24. Erdman KA, Fung TS, Doyle-Baker PK, Verhoef MJ, Reimer RA. Dietary supplementation of highperformance Canadian athletes by age and gender. Clin J Sport Med. 2007;17(6):458-64.

25. Laure P, Thouvenin F, Lecerf T. Attitudes of coaches towards doping. J Sports Med Phys Fitness. 2001;41(1):132-6.

26. Field A. Discovering Statistics Using IBM SPSS Statistics. Fourth edition ed. London: SAGE Publications Ltd; 2013.

27. Hanstad DV, Skille EÅ, Loland S. Harmonization of anti-doping work: myth or reality? Sport in Society. 2010;13(3).

28. Houlihan B. Achieving compliance in international anti-doping policy: An analysis of the 2009 World Anti-Doping Code. Sport Management Review. 2014;17:265-76.

29. Ivanova V, Miller JH, Rabin O, Squirrell A, Westwood S. Harmonization of anti-doping rules in a global context (World Anti-Doping Agency-laboratory accreditation perspective). Bioanalysis. 2012; 4(13):1603-11. 